Swarthmore College

Works

Fall 2016

\title{
Diversity In The Economics Profession: A New Attack On An Old Problem
}

Amanda Bayer

Swarthmore College, abayer1@swarthmore.edu

C. E. Rouse

Follow this and additional works at: https://works.swarthmore.edu/fac-economics

Part of the Economics Commons

Let us know how access to these works benefits you

\section{Recommended Citation}

Amanda Bayer and C. E. Rouse. (2016). "Diversity In The Economics Profession: A New Attack On An Old Problem". Journal Of Economic Perspectives. Volume 30, Issue 4. 221-242. DOI: 10.1257/jep.30.4.221 https://works.swarthmore.edu/fac-economics/420

This work is brought to you for free by Swarthmore College Libraries' Works. It has been accepted for inclusion in Economics Faculty Works by an authorized administrator of Works. For more information, please contact myworks@swarthmore.edu. 


\title{
Diversity in the Economics Profession: A New Attack on an Old Problem
}

\author{
Amanda Bayer and Cecilia Elena Rouse
}

he economics profession includes disproportionately few women and members of historically underrepresented racial and ethnic minority groups, relative both to the overall population and to other academic disciplines. In the United States, of 500 doctorate degrees awarded in economics to US citizens and permanent residents in 2014, only 42 were awarded to African Americans, Hispanics, and Native Americans and 157 to women (although this double-counts the 11 minority women who earned economics doctorates in 2014). This underrepresentation within the field of economics is present at the undergraduate level, continues into the ranks of the academy, and is barely improving over time. It likely hampers the discipline, constraining the range of issues addressed and limiting our collective ability to understand familiar issues from new and innovative perspectives.

In this paper, we first present data on the numbers of women and underrepresented minority groups in the profession. We then offer an overview of current research on the reasons for the underrepresentation, highlighting evidence that may be less familiar to economists. We argue that implicit attitudes and institutional practices may be contributing to the underrepresentation of women and minorities at all stages of the pipeline, calling for new types of research and initiatives to

- Amanda Bayer is Professor of Economics, Swarthmore College, Swarthmore, Pennsylvania. Cecilia Elena Rouse is Lawrence and Shirley Katzman and Lewis and Anna Ernst Professor in the Economics of Education and Dean of the Woodrow Wilson School of Public and International Affairs, Princeton University, Princeton, New Jersey. Their email addresses are abayer1@swarthmore.edu and rouse@princeton.edu.

${ }^{\dagger}$ For supplementary materials such as appendices, datasets, and author disclosure statements, see the article page at

http://dx.doi.org/10.1257/jep.30.4.221

doi $=10.1257 /$ jep.30.4.221 
attack the problem. We then review evidence on how diversity affects productivity and propose remedial interventions as well as findings on effectiveness. We identify several promising practices, programs, and areas for future research. The Journal of Economic Perspectives last addressed underrepresentation by women and racial and ethnic minorities in the economics profession over ten years ago (Ginther and Kahn 2004; in this journal, see also Leeds 1992; Kahn 1995; Collins 2000). Given the growing evidence that diversity matters, it is time for a renewed focus on increasing the diversity of the economics profession.

\section{The Gender and Racial/Ethnic Composition of the Economics Profession}

We focus on groups that have been historically underrepresented in the economics profession and in the United States: women, African Americans, Hispanics/Latinos, and Native Americans. Underrepresentation in the economics profession by these groups is longstanding and there is a growing literature addressing its scope and possible remedies. Of course, this list does not encompass all dimensions of diversity, and the problems facing various underrepresented groups differ in some ways. But as we learn about barriers faced by members of these groups and interventions to address them, we hope to develop insights that are transferrable to facilitating the inclusion of the best people and ideas from all groups. I]

According to the most recent survey conducted by the American Economic Association, 23.5 percent of tenured and tenure-track faculty in economics are women. ${ }^{2}$ As such, gender diversity in the academic economics profession is as poor as both the male-dominated tech industry and the Academy Awards nominating committee, where only 30 percent of the Silicon Valley workforce and 24 percent of Oscar voters are female. By rank, women represent 15 percent of full professors in economics departments and 31 percent of economics faculty at the assistant level.

The gender gaps in tenure and promotion rates in economics are much greater than those in the social sciences overall: specifically, Ginther and Kahn (2014) report a 20 percent gender gap in achieving tenure and a 50 percent gap

\footnotetext{
${ }^{1}$ This paper examines disparities by race/ethnicity and gender, but independently. We acknowledge, but do not examine here, the complicated intersectionality of race, ethnicity, and gender (Brewer, Conrad, and King 2002).

${ }^{2}$ Statistics on economics faculty are authors' calculations from the Universal Academic Questionnaire, a survey conducted annually by the American Economic Association (Scott and Siegfried 2016). The questionnaire asks respondents to report gender for all faculty members and race/ethnicity only for US citizens and permanent residents. The data must be interpreted with caution due to a low response rate (about 50 percent) and missing data. Nevertheless, the magnitudes are consistent with those produced in other years and in other surveys. The survey likely mismeasures gender, race, and ethnicity, because it does not use self-identification (department chairs list the gender and race of department members) and because the AEA survey relies on a gender binary (in contrast, for example, to the American Sociological Association's six gender response options).
} 
in promotion to full professor among economists compared to 12 percent and 25 percent, respectively, in the social sciences overall. More sobering, economics boasts the largest (or only) gender gaps in tenure rates, salaries, and job satisfaction compared to other math-intensive fields (Ceci, Ginther, Kahn, and Williams 2014). Moreover, Ceci, Ginther, Kahn, and Williams (2014) find that female full professor salaries in economics as a proportion of male salaries dropped from 95 percent in 1995 to less than 75 percent in 2010. In an analysis of published scholarly research across 21 academic disciplines, women accounted for 13.7 percent of authorships in economics since 1990, barely above the 12.0 percent in philosophy and well below the overall average of 27.2 percent (West, Jacquet, King, Correll, and Bergstrom 2013).

Minority academic economists are even rarer. While about 30 percent of the US population is black or Hispanic, only 6.3 percent of tenured and tenure-track economics faculty is identified as such (only 4.0 percent of full professors and 8.1 percent of assistants).$^{3}$ Price (2009) reports that in 2006, only 44 black economists were on the faculties of the $106 \mathrm{PhD}$-granting economics departments ranked by the National Research Council, and six of those black economists were employed at Howard University, a historically black university.

The pool from which economics departments pull new faculty members is not much different. Figure 1 shows the percentage of doctorate degrees awarded to women (panel A) and to minorities (panel C) between 1995 and 2014, using data on US citizens and permanent residents only, as collected by the National Center for Education Statistics. Figure 1A shows that while there was some progress in the representation of women between 1995 (when women represented 30.5 percent of new PhDs) and 2005 (when women represented 37.2 percent of new PhDs), some ground has been lost as just 31.4 percent of doctorates in economics were awarded to women in 2014. Even when including temporary-resident students, the percentage of doctorate degrees awarded to women, regardless of citizenship status, is only slightly greater (34.2 percent in 2014) and varies considerably across institutions. (For example, within the top ten programs, the percentage of doctorates awarded to women over the last three years ranges from a high of 40.8 percent to a low of 4.9 percent.) Figure 1A also shows that the percentage of women earning doctorates has stagnated in economics, while it has increased in other social science fields, humanities, business and management, and also in STEM (science, technology, engineering, and math) fields.

Figure $1 \mathrm{C}$ shows that the story is mostly similar when we look at the percentage of doctorates awarded to minorities (meaning black, Hispanic, or Native American) between 1995 and 2014. Between 1995 and 2007, there was steady improvement in the percentage of new doctorates in economics awarded to minorities, from 6.3 percent in 1995 to 11.4 percent in 2007. Since then, the percentage of new doctorates awarded to minorities has dropped substantially to only about 7 percent,

\footnotetext{
${ }^{3}$ Another 13 percent of tenured and tenure-track faculty is identified as US citizens or permanent residents of Asian ethnicity. About 5 percent of the general population in the United States is Asian.
} 
Figure 1

\section{Degrees Awarded to Women and Underrepresented Minorities}

A: Percentage of Doctorate Degrees

Awarded to Women

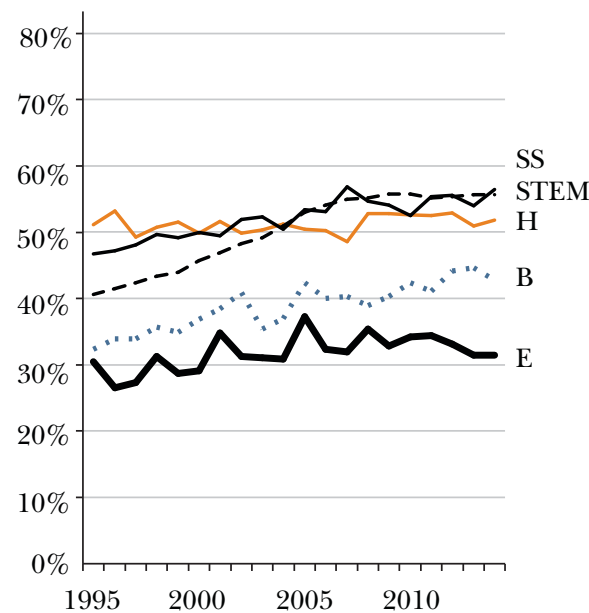

C: Percentage of Doctorate Degrees Awarded to Minority Students

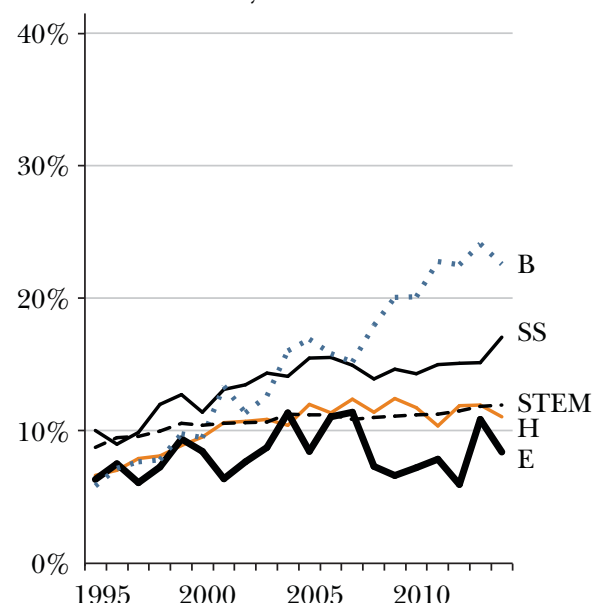

B: Percentage of Bachelor's Degrees Awarded to Women

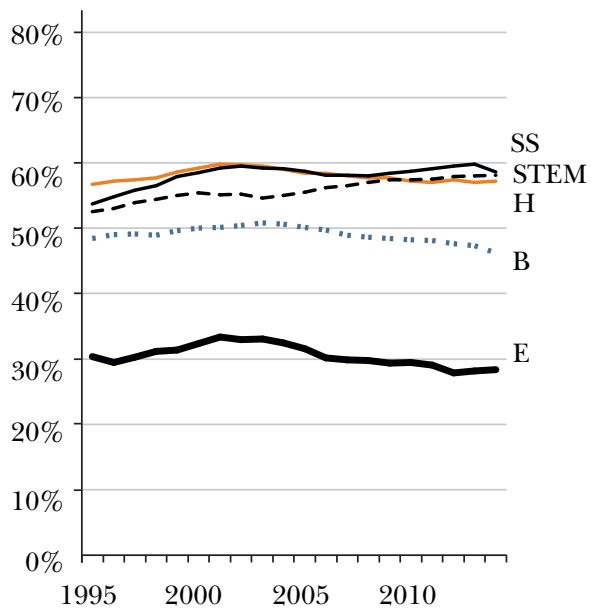

D: Percentage of Bachelor's Degrees Awarded to Minority Students

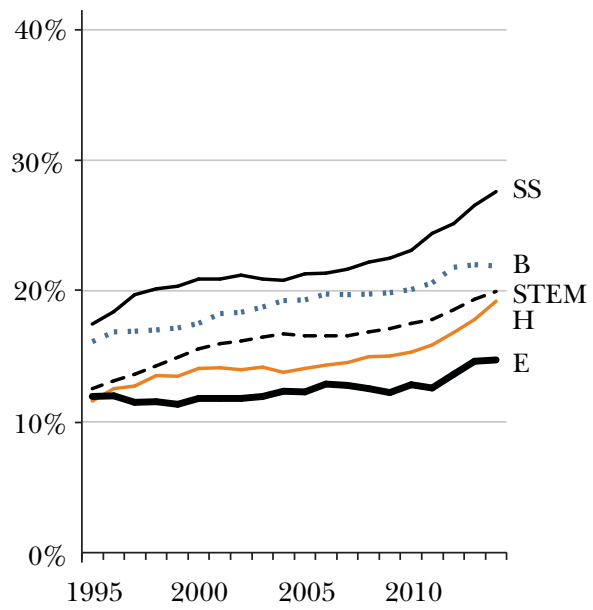

$$
\begin{array}{|l}
\hline \text { Social Science (SS) } \\
\hdashline \ldots \text { Business (B) }
\end{array}
$$

Note: Data are authors' calculations from the Integrated Postsecondary Education Data System (IPEDS) at the National Center for Education Statistics, using data on US citizens and permanent residents only. Economics degrees are classified as those with IPEDS Classification of Instructional Program codes for "Economics, General," "Agricultural Economics," "Applied Economics," "Econometrics and Quantitative Economics," "Development Economics and International Development," "International Economics," and "Economics, Other." We use the National Science Foundation definition of STEM (Science, Technology, Engineering, and Math) subjects, but exclude the social sciences to present that series separately. "Social Science" indicates social science fields but excludes degrees in economics. "Business" denotes business and management disciplines. Minority students are those who self identify as Hispanic or Latino, American Indian or Alaska Native, or Black or African American. 
although in 2014, 8.4 percent of new doctorates were awarded to minorities. (When including temporary-resident students, US minorities earned 3.5 percent of all economics PhDs awarded in the United States in 2014.) Further, Figure 1C shows that progress in increasing racial and ethnic diversity has been faster in other fields.

These disparities are evident at earlier stages in the pipeline as well. Figures 1B and 1D show the percentage of bachelor's degrees awarded to women and to minorities in various fields between 1995 and 2014. Again, there is little progress in increasing the percentage of female students graduating with bachelor's degrees in economics over the past two decades, with 28.4 percent (30.9 percent when including temporary residents) of degrees awarded to women in 2014. While there has been progress in other fields-including STEM-business and management displays the same lack of progress seen in economics.

Finally, while there has been some improvement in the percentage of minority students graduating with a major in economics, from 12 percent in 1995 to 14.7 percent in 2014, this rate is still far below the prevalence of this population among college students (22 percent of bachelor's degrees were awarded to minorities in 2014) and also below the 20 percent of bachelor's degrees awarded in STEM fields.

Overall, the economics profession has made little progress in the last two decades in diversifying the profession in key dimensions of gender, race, and ethnicity. These patterns stand in contrast to the robust and increasing representation of foreign-born individuals in US departments of economics. For example, the percentage of all US economics doctorate degrees awarded to temporary visa holders increased from 49 percent in 1995 to 59 percent in 2014, with half of these degrees going to temporary visa holders self-reporting Asian ethnicity on the NSF Survey of Earned Doctorates. (Simultaneously, the percentage of all US economics doctorate degrees awarded to non-Hispanic Asian citizens and permanent residents decreased from 6.6 percent in 1995 to 5.0 percent in 2014.) Though many of these students do not stay in the country after graduation, about one-third of new PhDs holding temporary visas have definite employment commitments in the United States (NSF Survey of Earned Doctorates, Table 51). So while the profession may not have made progress in all dimensions of diversity, it has in some. Nevertheless, concern with racial and ethnic diversity is inextricably linked to the history of race and ethnicity in the United States and to the pervasive and persistent barriers faced by African Americans, Hispanics, and Native Americans in this country. While students and faculty who come to the United States from abroad explicitly to study or teach economics have certainly faced challenges of their own and will face many more here as well, their experiences are fundamentally different from those of people who have lived a good portion of their lives in the country.

The relative absence of women and members of racial and ethnic minority groups in economics begins at the undergraduate level and then continues through doctoral education and beyond. The lethargic trends, along with the significant disparities that continue to exist throughout the pipeline from economics majors to economics professors, suggest that change is unlikely to be sustained-or perhaps to occur at all—without purposeful action. 


\section{Barriers to Diversity}

Why are there relatively few women and certain racial/ethnic minorities in the economics profession? We start by summarizing the literature on factors that affect the supply of individuals choosing economics as a field of study or profession, such as mathematics preparation and prior exposure to the field. We then turn to a review of evidence, some of it newer and less familiar, on the role of the demand side. We emphasize that by "demand side," we refer to the behavior of economists at all points along the pipeline, not only when hiring new PhDs but also at points before, such as attracting undergraduates to the major, and after, as careers are advanced or not.

\section{Supply-Side Factors}

The evidence in the previous section makes a prima facie case that the reason for the underrepresentation of women and minorities among $\mathrm{PhD}$ economists traces back to decisions made at the undergraduate level. Thus, a small, but growing, number of articles attempt to understand the factors that affect the decision to study economics, particularly by undergraduates. Common hypotheses focus on the effects of math preparation or aptitude, prior exposure to economics, performance in economics relative to other courses, and instructor race or gender. Most of this literature is based on correlational regression analysis of surveys or administrative data, either from an individual college or from a subset of colleges for which data were available. This research suggests that some explanations are more likely than others, without reaching a definitive conclusion.

For example, the level of math preparation does not seem to explain the underrepresentation within economics. The research generally finds that prior math preparation (as proxied by SAT/ACT scores or by questions that ask about comfort level with math), while affecting the decision by any student to take a class or major in economics, explains, at best, a small part of the underrepresentation in economics by women and minority students. In one study, Emerson, McGoldrick, and Mumford (2012) analyze a database with extensive information on undergraduate courses for 11 large state universities and find that gender differences in taking economics courses after the introductory course are not accounted for by measures of aptitude, or by an array of other variables. This conclusion is consistent with Integrated Postsecondary Education Data System (IPEDS) data showing that in 2014 women earned 42.6 percent of bachelor's degrees in mathematics and statistics, far beyond their 28.4 percent share in economics.

Several studies consider the role of prior exposure to economics in the decision to pursue further study. Dynan and Rouse (1997) find that women in their junior and senior years of college were more than twice as likely as men to report that they did not take economics in their first year because they "did not think that economics was interesting." This result is consistent with the findings of Calkins and Welki (2006) who report that perceived interest in the subject is a key factor in determining the choice of undergraduate major. Of course, such research 
raises questions of how perceptions of economics vary across undergraduates from different groups, which, if any, are accurate, and how we might provide better information about what economics is and the range of topics economists study.

Performance in early economics courses-such as introductory courses-and especially relative to performance in other courses may also be related to the decision to persist in economics. Rask and Tiefenthaler (2008), using 16 years of data from a liberal arts college where economics is a prominent major, find that women are more responsive to their relative grades in economics than are men. Of course, if this response exists across economics departments, it is likely related to the specific context of economics, including advising practices: if women were universally more responsive to relative grades, then they would also be more averse to majoring in math and science, where grades tend to be low (for example, see Butcher, McEwan, and Weerapana 2014, in this journal), but where female representation is higher than in economics.

Many point to the lack of role models in the profession as deterring both women and minorities from further consideration of economics. Instructor identity could affect student performance through a variety of possible mechanisms. Perhaps students are inspired by the role model or less subject to stereotype threat (Steele and Aronson 1995) in the presence of a stereotype-defying economist. ${ }^{4}$ Alternatively, professors with different life experiences may talk about different economic issues and in ways that resonate with different students. While earlier evidence on the effects of same-gender and same-race instructors had been mixed, more recent studies find that instructor identity makes some difference. For example, Dynan and Rouse (1997) look at data from Harvard University and report that having a female teacher at the introductory economics level had only a small impact on the decision to subsequently major in economics. In contrast, Hale and Regev (2014) conclude that a larger share of women on the economics faculty of top universities leads to more female students entering economics $\mathrm{PhD}$ programs, using the number of resignations of male faculty members as an instrumental variable to capture exogenous variation in the share of women in the faculty. Carrell, Page, and West (2010) analyze data from the US Air Force Academy, where students are randomly assigned to professors, and find female students perform significantly better in introductory math and science courses if taught by female faculty, and they are more likely to pursue majors in science, technology, engineering, or math. Fairlie, Hoffmann, and Oreopoulos (2014) find similar effects for underrepresented minority college students at a large and diverse community college, whose short and longer-term outcomes improve from taking courses with underrepresented minority instructors.

\footnotetext{
4 "Stereotype threat" is a robust and widely replicated phenomenon. A considerable body of research shows that "performance in academic contexts can be harmed by the awareness that one's behavior might be viewed through the lens of racial stereotypes" (Steele and Aronson 1995). Stereotype threat has been documented to diminish the academic performance of members of groups subject to negative stereotypes, including African Americans, Latinos, and women (Gonzales, Blanton, and Williams 2002; Inzlicht and Schmader 2012). White men are subject to stereotype threat on a math test when led to believe the test is being used to examine Asian superiority at math (Aronson et al. 1999).
} 
Because these last two studies do not focus on economics, future research might investigate the effects within economics specifically, as well as how to reproduce the benefits of faculty role models before having sufficient numbers of women and minority economists in place.

\section{Demand-Side Factors}

Most academic institutions have policies that officially encourage diversity in outreach, hiring, and promotion, and most academics have sat in numerous meetings where such concerns were expressed. Thus, claims that explicitly discriminatory attitudes on the demand side of academia play a role are often met with skepticism. Explicitly discriminatory behavior and attitudes may occur less frequently than in the past, but that does not mean they no longer exist. Perhaps more importantly, researchers in the last 30 years have been investigating implicit bias, a form of discrimination based on unconscious attitudes or associations, which can produce behavior that diverges from the individual's own endorsed beliefs or principles. A common method for exploring unconscious attitudes is an "Implicit Association Test" (Greenwald, McGhee, and Schwartz 1998), in which subjects are instructed to make associations between various words or images very quickly and then see what patterns and connections emerge. ${ }^{5}$ In contrast, most investigations by economists of demand-side causes of disparities-like models of taste-based discrimination and statistical discrimination-focus on situations in which the discriminator makes an explicit decision (for reviews, see Darity and Mason 1998 in this journal; Lang and Lehmann 2012). While much of the work on implicit associations and discrimination has not involved economists as subjects or as researchers, we believe the evidence has implications for the economics profession and for future economic research.

A substantial body of evidence documents the pervasiveness of implicit biases reflecting social stereotypes (for surveys of the evidence, see Greenwald and Banaji 1995; Greenwald and Krieger 2006). This work is consistent with the research in economics by Bertrand and Mullainathan (2004), which involved responding to newspaper help-wanted ads with fictitious resumes showing similar credentials but a mixture of names that potential employers were likely to associate with African Americans or with whites. White-sounding names were much more likely to get callbacks. Bertrand, Chugh, and Mullainathan (2005) discuss how such findings can result from implicit discrimination.

Implicit biases have been shown to affect professional judgment across a range of professions. For example, Schulman et al. (1999) describes a study in which

\footnotetext{
${ }^{5}$ Researchers hypothesize that the human brain uses implicit association to deal with bottlenecks in information processing; in the visual system, for instance, the retina receives information at an estimated rate of 109 bits per second (Kelly 1962), far beyond the 30 to 50 bits per second processing capacity of deep layers of the visual pathway (Sziklai 1956). Response latency tests, priming studies, and direct measurement of physiological and neurological reactions indicate that race, gender, and other perceived group affiliations operate as heuristics, with powerful, unconscious effects on judgments and actions. Try taking a test yourself at https://implicit.harvard.edu/implicit/education.html.
} 
720 doctors watched videos of "patients" describing chest pain symptoms. Although the actors were scripted to convey a very similar range of information, the doctors were more likely to refer whites and men for cardiac catheterization than blacks and women. In an Internet-based study of the responses of 287 physicians at four medical centers to a hypothetical patient presenting with acute coronary symptoms, Green et al. (2007) find that physicians with greater pro-white implicit bias, as measured by an array of implicit association tests, were less likely to treat black patients with thrombolysis (an immediate treatment to dissolve blood-clots) relative to whites with the same symptoms, despite reporting no explicit bias in a survey about prejudice.

Research suggests that implicit bias affects interactions at all stages of the academic pipeline, in formal decisions, such as promotion and admission, and in routine interactions, such as advising students on courses to take or responding to questions and ideas from colleagues. In a study by Milkman, Akinola, and Chugh (2015), 6,500 professors in 89 disciplines across 259 US universities received an email with a request from a fictional prospective student, asking for a 10-minute meeting to discuss research opportunities prior to applying to a doctoral program. The student's name was randomly assigned to signal gender and race (Caucasian, Black, Hispanic, Indian, Chinese), but messages were otherwise identical. Across almost all disciplines, faculty ignored requests from women and minorities at higher rates than requests from Caucasian males, with large and statistically significant regression-estimated discriminatory gaps. In business, the discipline with the largest gap, 87 percent of Caucasian males received a response, compared to 62 percent of women and minorities. In the social sciences, which in this study pools economics with 18 other disciplines including sociology, communication, and gender and area studies, 75 percent of Caucasian males received a response, compared with 68 percent of women and minorities. Follow-up analyses revealed that discriminatory gaps were particularly acute in higher-paying disciplines and in private institutions. Moreover, there was no evidence that women benefited from contacting female faculty, nor that black or Hispanic students benefited from contacting same-race faculty. ${ }^{6}$

A variety of studies suggest bias in academic hiring. Specifically, a sample of 127 science faculty in research universities rated a male applicant for a lab manager position as significantly more competent and hirable than an identical female applicant based on looking at a job application from a hypothetical job candidate who was randomly assigned to be male or female. They also selected a 15 percent higher starting salary and offered more career mentoring to male applicants (MossRacusin et al. 2012). Male and female faculty members were equally likely to exhibit bias. Similarly, after evaluating a curriculum vitae that was randomly assigned a male or female name, a sample of 238 male and female academic psychologists

\footnotetext{
${ }^{6}$ Implicit bias also affects the experience of enrolled students. Dee, John, Baker, and Evans (2015) find that instructors of massive open online courses (MOOCs) are more likely to respond to forum posts by ostensibly white male students.
} 
were more likely to hire the male applicant for a tenure-track job and had more positive evaluations of the male applicant's teaching, research, and service records (Steinpreis, Anders, and Ritzke 1999). In a study of high-achieving male professors in life sciences, Sheltzer and Smith (2014) find that they train 10-40 percent fewer women in their laboratories relative to others. Trix and Psenka (2003) analyze the content of 300 letters of recommendation for prospective faculty members at a large medical school in the 1990s, finding that letters for women are shorter, are more likely to use language that raises doubts, and reinforce gender stereotypes of women as teachers and men as researchers (for example, the phrases "her teaching" and "his research" are commonly used).

While we know of no experiments directly testing for bias amongst economists, a recent working paper by Sarsons (2015) provides evidence suggesting implicit bias in economics. Using data from the curricula vitae of economists who were up for tenure between 1975 and 2014 at the top $30 \mathrm{PhD}$-granting US universities, she documents that, while an additional coauthored paper for a man has the same effect on the likelihood of tenure as a solo-authored paper, women suffer a significant penalty for coauthoring, especially when their coauthors are men.

Women and minority faculty members can be subject to unconscious bias from evaluators other than colleagues, as well. Students rate instructors of online classes significantly higher when the instructors use a male identity than when they use a female identity, regardless of the instructors' actual gender (MacNell, Driscoll, and Hunt 2015; Boring, Ottoboni, and Stark 2016), and write gendered online reviews, using the word "brilliant" more often to describe male faculty and the word "annoying" to describe females, even in economics (see http://benschmidt.org/ profGender). In a study of referee recommendations using a large sample of articles submitted to one economics journal, Abrevaya and Hamermesh (2012) find no evidence of relative favoritism by referees towards authors of their own gender. It is important to note, however, that regression analyses that assess discrimination using same-gender interaction terms cannot actually detect bias to the extent that both male and female evaluators are influenced by social stereotypes about women, as other studies have repeatedly shown.

Finally, there is a possibility of "institutional discrimination," which occurs when the rules, practices, or "nonconscious understandings of appropriate conduct" systematically advantage or disadvantage members of particular groups (Haney-López 2000). We use this phrase to describe the (not explicitly intended) discrimination that occurs when facially neutral policies and routines of an academic department or instructor have, in practice, a disparate impact by gender or race. For example, a de facto practice to hire candidates only from elite $\mathrm{PhD}$ programs (or to admit $\mathrm{PhD}$ applicants only from elite undergraduate institutions) may produce systematic disadvantage. Indeed, economists do in fact display a high propensity to hire from top ten graduate programs as compared to other disciplines (Wu 2005). Alternatively, the use of a decision rule eliminating all junior job candidates who took more than six years to complete their PhD would disproportionately impact members of racial and ethnic minority groups, 
and to some extent women, for whom longer times to $\mathrm{PhD}$ completion are more likely. More generally, a narrow vision of the appropriate route to excellence as an economist undervalues the alternative pathways taken by women and minorities towards academic careers (Turner and Myers 2000; Husbands Fealing, Lai, and Myers 2015).

Institutional policies can cause unplanned, but ultimately unsurprising, disadvantage. An analysis of data on all assistant professors hired at top-50 economics departments from 1985 to 2004 found that gender-neutral policies to stop the tenure clock for new parents substantially reduce female tenure rates while substantially increasing male tenure rates (Antecol, Bedard, and Stearns 2016). As another example, desire to have women and minority representation on committees may help explain why women faculty are asked to provide more service, as a survey of 1,399 members of US political science departments found (Mitchell and Hesli 2013). Indeed, women associate professors spend far more time on service than do male associates, with estimates of the differential ranging from two to five hours a week, in studies of faculty in science and engineering at top research universities (Link, Swann, and Bozeman 2008) and in various disciplines at a large public university (Misra, Lundquist, and Templer 2011).

As a broader example of unintended disparate effects, perhaps economists are not in the habit of implementing undergraduate curricula and teaching techniques that would make economics more inclusive and meaningful for groups traditionally underrepresented in our profession. To the extent that economists are ineffective teachers, whether due to competing priorities or to lack of training, we end up with a self-selected sample of student majors who come to our classes with prior interest, background, and encouragement in economics.

Of course, posing these demand-side explanations raises the question of whether they can help explain why economics has been slower to diversify than other fields. The existing evidence on this point is not conclusive. However, it is concerning that those who, like economists, are used to framing choices in terms of individual objective decision-making may also be less vigilant against discrimination. Stephens and Levine (2011) look at attitudes about gender discrimination in the labor force in a sample of stay-at-home mothers and undergraduate students, and find that framing actions in terms of individual choice increases expressed belief that society provides equal opportunities and that discrimination no longer exists. Uhlmann and Cohen (2007) analyze a group of 65 men who role-played a game about hiring a factory manager, in which they rated a job applicant who could randomly be male or female. Some of the men were "primed" in advance by being asked to answer a survey about whether they viewed themselves as objective and logical. Those who were "primed" in this way were more likely to favor male applicants.

Overall, the potential importance of demand-side considerations in economics is suggested by one of the findings in Ceci, Ginther, Kahn, and Williams (2014), who find that across most fields with a heavy focus on math skills, "the research indicates no significant sex differences in promotion to tenure and full professor." However, 
they also write: "Economics is an outlier, with a persistent sex gap in promotion that cannot be readily explained by productivity differences." "7]

\section{Why Economists Should Care about Diversity}

Why should economists care about the underrepresentation of women and members of minority groups in their profession? Broadening the pool from which professional economists are drawn is not just about fairness, important though this is. Two strands of recent research suggest that it is also necessary to ensure the profession produces robust and relevant knowledge.

First, opinions among economists about policy are not the same across different groups. In a survey of 143 AEA members with doctoral degrees from US institutions, May, McGarvey, and Whaples (2014) find that male and female economists have different views on economic outcomes and policies, even after controlling for vintage of $\mathrm{PhD}$ and type of employment. For example, relative to male economists, women economists are 21 percentage points more likely to disagree that the United States has excessive government regulation of economic activity; 32 percentage points more likely to agree with making the distribution of income more equal; 30 percentage points more likely to agree that the United States should link import openness to labor standards; and 42 percentage points more likely to disagree that labor market opportunities are equal for men and women. The prevailing range of views among economists is likely to be biased by the relative lack of women and minority economists.

Second, diversity changes group dynamics and decision-making, and the behavior of individual members changes with the mix of the group. A body of laboratory experiments on this point has been done with a wide range of players and tasks. In studies focusing on the effects of gender diversity, Woolley et al. (2010) recruited 699 people in Boston and Pittsburgh and put them to work in groups ranging in size from two to five on a series of problem-solving tasks. They find that the more successful groups display a "collective intelligence" that is based not on the intelligence of individual members, but on the social sensitivity of the group, in taking turns in conversation, and on the proportion of females in the group. Hoogendoorn, Oosterbeek, and van Praag (2013) randomly assign 550 undergraduate business students in Amsterdam to course project groups and find that mixed-gender groups display more intense mutual monitoring and produce better outcomes in a business-oriented scenario. Kamas, Preston, and Baum (2008) look at a group of 164 undergraduate students playing a "dictator"

\footnotetext{
${ }^{7}$ It is also worth noting that regression analyses attributing differences in outcomes to productivityrelated factors likely underestimate discriminatory gaps, given the pervasive effects of gender and racial/ ethnic biases. For example, in regressions explaining the likelihood of promotion to full professor, unconscious bias likely affects control variables such as course evaluations and publication record as well as the estimated coefficients on gender and race variables.
} 
game in which they must split a sum of money between themselves and the American Red Cross. Women tend to give more than men, and a two-person male-female team gives more than the expected sum of what they would give playing alone.

In examples of studies looking at ethnic and cultural diversity, Phillips, Northcraft, and Neale (2006) show in an experimental setting with 216 undergraduate business students that racially diverse groups significantly outperform other groups in solving complex problems, as homogeneous groups perceive their information to be less unique and spend less time on the task. In a study with 200 jury-eligible Michigan community members, Sommers (2006) found that participants on racially diverse mock juries exchange more information, make fewer errors, deliberate longer, and consider a wider range of perspectives. Levine et al. (2014) conduct a laboratory experiment involving a scenario with potential price bubbles using groups of real world traders in two locations, one in Southeast Asia and one in North America. They find that traders in ethnically homogeneous markets place undue confidence in the reasonableness of others' decisions, which leads to price bubbles, while ethnic diversity can promote deliberation and disrupt conformity. Leung, Maddux, Galinsky, and Chiu (2008) offer a review of the evidence from the psychology literature that exposure to multiple cultures can enhance creativity.

The commonality of findings about diversity in many contexts is notable, but of course these studies are not directly about decision-making in academia. In a study that suggests that the creativity and productivity of mixed groups may also benefit academic research, Freeman and Huang (2015) examine 2.5 million research papers written from 1985 to 2008 in which all of the authors had US addresses. They find that papers written by ethnically diverse research teams receive more citations and are higher impact than papers written by authors from the same ethnic group. Although noncausal explanations of this pattern are possible, it suggests that greater diversity of authorship may lead to higher quality research.

If the ultimate goal of economic research is to develop and communicate lasting insights, this evidence suggests that the value and impact of the economics profession suffer from the lack of diversity in its ranks.

\section{Moving Forward}

We believe there are several promising directions for future initiatives and research.

\section{Revise How We Present Economics to Undergraduates}

The economics profession needs to attract a larger share of women and minorities into economics at the undergraduate level. We highlight several recommended approaches here. Much of the evidence behind these approaches comes from randomized control trial studies in science, technology, engineering, and math 
fields. We encourage economists to use and expand the body of research on best teaching practices in economics. ${ }^{8}$

Undergraduate economics continues to be taught primarily in a lecture format. Watts and Schaur (2011), for instance, show in survey data with about 400 academic economists as respondents that traditional lecturing, a practice that has been shown repeatedly to be inferior to other available methods, remains the dominant undergraduate teaching method among economists. The survey also shows that references to "gender, race, and ethnic issues" in undergraduate economics courses are rare. The alternative to a lecture format is active learning, in which instructors ask rather than tell, and students answer questions in discussions or with clickers, clarify concepts to each other via peer instruction, and discover principles through classroom experiments and labs. Freeman et al. (2014) carries out a meta-analysis of 225 studies comparing the effects of active and passive learning techniques in science, technology, engineering, and mathematics. They find that active learning increases exam scores and decreases failure rates relative to traditional lecturing, with particular benefit for students from disadvantaged backgrounds and for women in male-dominated fields.

Instructors can reduce stereotype threat with an array of empirically validated strategies, many of which suggest that what may seem like relatively small changes can have substantial effects. For example, Murphy, Steele, and Gross (2007) had 47 Stanford University undergraduates watch one of two videos about a math, science, and engineering conference. Some viewed a video in which men outnumbered women in a ratio of 3 to 1 , while others observed gender balance in an otherwise identical video. Women who saw the gender-balanced conference felt more sense of belonging and desire to participate than those who saw the gender-imbalanced version. Purdie-Vaughns et al. (2008), in experiments involving African American professionals, show that cues conveying that diversity is valued, rather than a colorblind philosophy, can help reduce identity-related threat in low minority representation environments. Miyake et al. (2010) carry out a "values affirmation" exercise with 399 college students in an introductory physics class and confirm that the treatment group, which selected and wrote about values important to them in two 15-minutes exercises, ended up with a lower male-female performance gap for the course as a whole. Such exercises, although unrelated to course content, have been shown to reduce the effects of stereotype threat for racial minorities, too. With these examples in mind, sharing the new AEA video on careers in economics (at http://www.aeaweb.org/video/career_in_economics.php) may be a useful step toward encouraging women and minority students in economics.

Good teachers remind students that intelligence is not a fixed trait and that economic ability can be developed through hard work, making mistakes, and perseverance. For example, in an experimental study Aronson, Fried, and Good (2002)

\footnotetext{
${ }^{8}$ For a review of studies about undergraduate teaching in economics, although with little attention to the diversity issues that are the focus here, a useful starting point is Allgood, Walstad, and Siegfried (2015). For more guidance on the design of undergraduate economics curricula, see Allgood and Bayer (2016).
} 
ask African American and white Stanford undergraduates to write to younger pen pals to emphasize, among other things, that intelligence is malleable, and they find that the treatment increases academic enjoyment, engagement, and performance for undergraduates in both racial groups, but particularly for African Americans. Departments making comprehensive changes can impact participation rates significantly. The Grinnell Science Project, the computer science program at Harvey Mudd College, and Princeton's Diversity Programs in Molecular Biology and Quantitative and Computational Biology use arrays of interventions to produce significant changes at the undergraduate and doctoral levels. Components include curricular reform, community building, student-faculty research, recruitment, holistic candidate review, and/or pre-orientation. At Harvey Mudd, the number of women computer science graduates quadrupled in six years (Alvarado, Dodds, and Libeskind-Hadas 2012).

There are a number of current projects to develop and evaluate best practices within economics. The AEA's Committee on the Status of Minority Groups in the Economics Profession sponsors an online resource, Diversifying Economic Quality at DiversifyingEcon.org, to help economics instructors and departments adopt inclusive, innovative, and evidence-based teaching practices (Bayer 2011). Another initiative is "The Undergraduate Women in Economics Challenge," directed by Claudia Goldin and funded by the Alfred P. Sloan Foundation, which provides guidance and significant funds to 20 treatment departments to explore and implement interventions designed to increase the number of women economics majors, while simultaneously tracking outcomes in a set of unfunded control departments. Other projects are using field experiments to evaluate the effectiveness of specific interventions intended to broaden participation in undergraduate economics. Through projects with rigorous experimental designs, we learn what works and what does not work in increasing the representation of women and minorities in economics, while also gaining greater insight into causal mechanisms and generating additional hypotheses to support future research and initiatives.

\section{Support Early-Career Pipeline and Mentoring Programs}

Pipeline programs help participants develop skills and networks critical to staying and moving forward in a field of study. The AEA supports several programs, and there now exists some credible evidence of their effectiveness. For example, the AEA's Committee on the Status of Women in the Economics Profession (CSWEP) sponsors a mentoring program for young female economists (CeMENT Mentoring Workshops) during which participants are placed into small groups based on their teaching and research and matched with a senior mentor to address issues such as effective teaching, navigating the journal publication process, balancing work and "life," and the tenure process. Blau, Currie, Croson, and Ginther (2010) conducted a randomized study of its effectiveness and report that the mentoring program had a positive effect on a number of professional outcomes, such as the number of toptier publications, the total number of publications, and the number of successful federal grants earned by individuals randomly assigned a mentor compared to those randomly assigned to the control group. 
Since 1974, the AEA's Committee on the Status of Minority Groups in the Economics Profession (CSMGEP) has sponsored a Summer Training Program aimed at improving diversity in the economics profession. The program, which has been hosted at a number of universities over time, runs about 7-8 weeks during which undergraduates take classes in microeconomic theory, math, and econometrics, and more recently have written research papers. The program has averaged about 25 students per year. Becker, Rouse, and Chen (2016) compared the outcomes of participants to those of unsuccessful applicants and find that Summer Program participants were significantly more likely to apply to and attend an economics $\mathrm{PhD}$ program, complete a PhD, and ever work in an economics-related academic job.

Both CSWEP and CSMGEP have other programs aimed at providing women and underrepresented minorities with greater mentorship (such as CSWEP's Mentoring Breakfast and CSMGEP's Mentoring Program) or opportunities to conduct guided research (such as the CSWEP/CSMGEP Summer Fellows Program). Another mentoring program currently housed at Duke University is the Diversity Initiative for Tenure in Economics (DITE), which aims to help untenured professors and economists outside of the academy to strengthen their research in order to attain tenure. Other recent efforts for early-stage economists include one-year pre-doctoral and master's programs, which are designed to enrich students' skills in math, economic theory, and econometrics to increase their likelihood of graduate program acceptance and success; the University of Wisconsin, the University of Texas at Austin, Duke University, Tufts University, the University of California at Los Angeles, Washington University, and Vanderbilt University currently offer such programs, to name a few. While these efforts have not yet been evaluated, well-designed bridge programs are used successfully in physics and other disciplines to increase the number of underrepresented minority students earning doctoral degrees (for example, Stassun et al. 2011). More generally, the economics profession would benefit greatly from additional studies with credible identification strategies to help estimate the effectiveness of these kinds of pipeline and mentoring programs.

\section{Remove Implicit and Institutional Barriers}

Research shows that implicit associations can be modified to produce outcomes more aligned with our values and intentions. In one prominent example, Pope, Price, and Wolfers (2014) show that racial patterns in personal foul calls by professional basketball referees disappeared following media attention to findings reported by Price and Wolfers (2010).

Laboratory experiments suggest that interventions can alter implicit attitudes. Devine, Forscher, Austin, and Cox (2012) study 91 nonblack undergraduate students who took a 12-week course to raise awareness of the existence and effects of implicit bias and to learn about an array of proven strategies for reducing bias. The students in the treatment group changed their scores on implicit bias tests about black-white associations, and the change persisted eight weeks after the end of the course. Research also suggests that altering decision-making procedures can 
limit the opportunity for bias to influence evaluations and behavior. A well-known example is the study by Goldin and Rouse (2000), which found that when auditions for professional orchestras occurred behind a screen, so that musicians were judged only on what they sounded like, the chances rose for women to be hired. More broadly, Soll, Milkman, and Payne (2014) review a range of literature on ways to "debias" judgments, which apply not only to attitudes about women and minorities in economics but also to the full array of behavioral decision biases. For example, we can create conditions for making less-biased evaluations by: removing identifiers, minimizing time pressure and distractions, discrediting feelings of connection or chemistry, committing to fair and relevant admissions or hiring criteria before learning applicants' race or gender, collecting more evidence on candidates' competencies, creating accountability, and strategically setting default options and other nudges. Efforts along these lines deserve further study and documentation.

Certain institutional features and practices that can act as barriers to diversity should be reconsidered. Conventional hiring and admissions standards-such as hiring exclusively (or almost exclusively) from elite $\mathrm{PhD}$ programs, getting referrals from traditional networks, and using test score cutoffs-may be better indicators of past background than of future potential. Indeed, using a minimum GRE score below which graduate school applicants are rejected without consideration of other information violates the test developer's guidelines (ETS 2015), and physicists are constructing alternative selection criteria more predictive of success in scientific research (for example, Miller and Stassun 2014). When developing criteria to evaluate candidates, colleagues, or students, the goal should be to set sufficiently broad and fundamental criteria to allow all types of candidates to reveal their strengths and potential. As colleagues, we can be allies to women and faculty of color by helping to relieve service burdens and making sure diverse types of work are valued. Using a combination of survey, field, and laboratory evidence, Vesterlund, Babcock, Recalde, and Weingart (2015) consider the allocation of "non-promotable tasks" (tasks irrelevant to advancement of an individual's career but necessary to the wellbeing of the group) and find that women more often are asked to do these tasks, and accept, due to commonly held beliefs that men are relatively less inclined to do them. More generally, the possibility of bias in the impact of the policies, shortcuts, and habits of individuals, departments, and administrations should be recognized and addressed.

In some ways, efforts to reduce bias ask nothing more than for academics to listen to the better angels of their nature. Fair and specific feedback, delivered with both an invocation of high standards and an assurance of the person's capacity to reach those standards, can counter stereotype threat and close racial gaps in perceived bias, motivation, and achievement, as Cohen, Steele, and Ross (1999) demonstrate in a study of 100 black and white Stanford undergraduates. A sensible, if untested, strategy to counter the everyday effects of unconscious bias is to crowd out micro-inequities with what Rowe (2008) calls "micro-affirmations," defined as small acts that occur, consciously or unconsciously, wherever people wish to help others to succeed. In interactions with colleagues and students, give credit to others, open doors to opportunity, listen, include, support, and encourage. 


\section{Conclusion}

We hope that these insights and results about diversity, drawn from bodies of research in multiple disciplines, help to suggest promising directions for future interventions and research, by economists and others. The evidence seems clear that the field of economics is behind others in its progress on diversity concerns, and our sense is that attending to what we have characterized as demand-side issues could have great payoffs. Recent methodological advances, especially in analyzing cognitive biases and in the use of laboratory and field experiments, provide new insights and opportunities for research into the benefits, barriers, and steps to a more diverse and inclusive profession.

The social science discipline of economics will be strengthened if it is built on a broader segment of the population. In October 2014, the Federal Reserve hosted a National Summit on Diversity in the Economics Profession, bringing together presidents and research directors of the Federal Reserve Banks and chairs of economics departments from around the country to open a professionwide dialogue about diversity. In her remarks at this event, Federal Reserve Chair Janet Yellen (2014) stated, "[W] hen economics is tested by future challenges, I hope that our profession will be able to say that we have done all we could to attract the best people and the best ideas."

- We thank Disa Hynsjo, Samsun Knight, and Nikhita Luthra for expert research assistance, Charles Scott for providing additional data from the Universal Academic Questionnaire, and the Princeton University Industrial Relations Section for funding. Any errors in fact or interpretation are ours.

\section{References}

Abrevaya, Jason, and Daniel S. Hamermesh. 2012. "Charity and Favoritism in the Field: Are Female Economists Nicer (to Each Other)?” Review of Economics and Statistics 94(1): 202-207.

Allgood, Sam, and Amanda Bayer. 2016. "Measuring College Learning in Economics." Chap. 1 in Improving Quality in American Higher Education: Learning Outcomes and Assessments for the 21st Century, edited by Richard Arum, Josipa Roksa, and Amanda Cook. San Francisco: Jossey Bass.

Allgood, Sam, William B. Walstad, and John J. Siegfried. 2015. "Research on Teaching Economics to Undergraduates." Journal of Economic Literature 53(2): 285-325.

Alvarado, Christine, Zachary Dodds, and Ran Libeskind-Hadas. 2012. “Increasing Women's Participation in Computing at Harvey Mudd College." ACM (Association for Computing Machinery) Inroads 3(4): 55-64.

Antecol, Heather, Kelly Bedard, and Jenna Stearns. 2016. "Equal but Inequitable: Who Benefits from Gender-Neutral Tenure Clock Stopping Policies?” IZA Discussion Paper 9904.

Aronson, Joshua, Carrie B. Fried, and Catherine 
Good. 2002. "Reducing the Effect of Stereotype Threat on African American College Students by Shaping Theories of Intelligence." Journal of Experimental Social Psychology 38(2): 113-125.

Aronson, Joshua, Michael J. Lustina, Catherine Good, Kelli Keough, Claude M. Steele, and Joseph Brown. 1999. "When White Men Can't Do Math: Necessary and Sufficient Factors in Stereotype Threat." Journal of Experimental Social Psychology 35(1): 29-46.

Bayer, Amanda, ed. 2011. Diversifying Economic Quality: A Wiki for Instructors and Departments. The AEA Committee on the Status of Minority Groups in the Economics Profession. http:/ / www.diversifyingecon.org (accessed June 1, 2015).

Becker, Charles M., Cecilia Elena Rouse, and Mingyu Chen. 2016. "Can a Summer Make a Difference? The Impact of the American Economic Association Summer Program on Minority Student Outcomes." Economics of Education Review 53: 46-71.

Bertrand, Marianne, Dolly Chugh, and Sendhil Mullainathan. 2005. "Implicit Discrimination." American Economic Review 95(2): 94-98.

Bertrand, Marianne, and Sendhil Mullainathan. 2004. "Are Emily and Greg More Employable than Lakisha and Jamal? A Field Experiment on Labor Market Discrimination." American Economic Review 94(4): 991-1013.

Blau, Francine D., Janet M. Currie, Rachel T. A. Croson, and Donna K. Ginther. 2010. "Can Mentoring Help Female Assistant Professors? Interim Results from a Randomized Trial." American Economic Review 100(2): 348-52.

Boring, Anne, Kellie Ottoboni, and Philip Stark. 2016. "Student Evaluations of Teaching (Mostly) Do Not Measure Teaching Effectiveness." ScienceOpen Research, doi:10.14293/ S2199-1006.1.SOR-EDU.AETBZC.

Brewer, Rose M., Cecilia A. Conrad, and Mary C. King. 2002. "The Complexities and Potential of Theorizing Gender, Caste, Race, and Class." Feminist Economics 8(2): 3-17.

Butcher, Kristin F., Patrick J. McEwan, and Akila Weerapana. 2014. "The Effects of an Anti-GradeInflation Policy at Wellesley College." Journal of Economic Perspectives 28(3): 189-204.

Calkins, Lindsay Noble, and Andrew Welki. 2006. "Factors that Influence Choice of Major: Why Some Students Never Consider Economics." International Journal of Social Economics 33(8): 547-64.

Carrell, Scott E., Marianne E. Page, and James E. West. 2010. "Sex and Science: How Professor Gender Perpetuates the Gender Gap.” Quarterly Journal of Economics 125(3): 1101-44.

Ceci, Stephen J., Donna K. Ginther, Shulamit Kahn, and Wendy M. Williams. 2014. "Women in
Academic Science: A Changing Landscape." Psychological Science in the Public Interest 15(3): 75-141.

Cohen, Geoffrey L., Claude M. Steele, and Lee D. Ross. 1999. "The Mentor's Dilemma: Providing Critical Feedback across the Racial Divide." Personality and Social Psychology Bulletin 25(10): 1302-18.

Collins, Susan M. 2000. "Minority Groups in the Economics Profession." Journal of Economic Perspectives 14(2): 133-48.

Darity, William A., and Patrick L. Mason. 1998. "Evidence on Discrimination in Employment: Codes of Color, Codes of Gender." Journal of Economic Perspectives 12(2): 63-90.

Dee, Thomas, June Park John, Rachel Baker, and Brent Evans. 2015. "Bias in Online Classes: Evidence from a Field Experiment." 37th Annual Fall Research Conference, titled "The Golden Age of Evidence-Based Policy," held November 12-14, 2015, in Miami, Florida. https://appam.confex. com/appam/2015/webprogram/Paper12412. html.

Devine, Patricia G., Patrick S. Forscher, Anthony J. Austin, and William T. L. Cox. 2012. "Long-Term Reduction in Implicit Race Bias: A Prejudice Habit-Breaking Intervention.” Journal of Experimental Social Psychology 48(6): 1267-78.

Dynan, Karen E., and Cecilia Elena Rouse. 1997. "The Underrepresentation of Women in Economics: A Study of Undergraduate Economics Students." Journal of Economic Education 28(4): 350-68.

Educational Testing Service (ETS). 2015. GRE: Guide to the Use of Scores. http:/ / www.ets.org/s/gre/ pdf/gre_guide.pdf.

Emerson, Tisha L. N., KimMarie McGoldrick, and Kevin J. Mumford. 2012. "Women and the Choice to Study Economics." Journal of Economic Education 43(4): 349-62.

Fairlie, Robert W., Florian Hoffmann, and Philip Oreopoulos. 2014. "A Community College Instructor Like Me: Race and Ethnicity Interactions in the Classroom." American Economic Review 104(8): 2567-91.

Freeman, Richard B., and Wei Huang. 2015. "Collaborating with People Like Me: Ethnic Coauthorship within the United States." Journal of Labor Economics 33(S1): S289-S318.

Freeman, Scott, Sarah L. Eddy, Miles McDonough, Michelle K. Smith, Nnadozie Okoroafor, Hannah Jordt, and Mary Pat Wenderoth. 2014. "Active Learning Increases Student Performance in Science, Engineering, and Mathematics." PNAS 111(23): 8410-15.

Ginther, Donna K., and Shulamit Kahn. 2004. "Women in Economics: Moving Up or Falling Off the Academic Career Ladder?" Journal of Economic Perspectives 18(3): 193-214. 
Ginther, Donna K., and Shulamit Kahn. 2014. "Academic Women's Careers in the Social Sciences." Chap. 11 in The Economics of Economists, edited by Alessandro Lanteri and Jack Vromen. Cambridge University Press.

Goldin, Claudia, and Cecilia Rouse. 2000. "Orchestrating Impartiality: The Impact of 'Blind' Auditions on Female Musicians." American Economic Review 90(4): 715-41.

Gonzales, Patricia M., Hart Blanton, and Kevin J. Williams. 2002. "The Effects of Stereotype Threat and Double-Minority Status on the Test Performance of Latino Women." Personality and Social Psychology Bulletin 28(5): 659-70.

Green, Alexander R., Dana R. Carney, Daniel J. Pallin, Long H. Ngo, Kristal L. Raymond, Lisa I. Iezzoni, and Mahzarin R. Banaji. 2007. "Implicit Bias among Physicians and Its Prediction of Thrombolysis Decisions for Black and White Patients." Journal of General Internal Medicine 22(9): 1231-38.

Greenwald, Anthony G., and Mahzarin R. Banaji. 1995. "Implicit Social Cognition: Attitudes, Self-esteem, and Stereotypes." Psychological Review 102(1): 4-27.

Greenwald, Anthony G., Debbie E. McGhee, and Jordan L. K. Schwartz. 1998. "Measuring Individual Differences in Implicit Cognition: The Implicit Association Test." Journal of Personality and Social Psychology 74(6): 1464-80.

Greenwald, Anthony G., and Linda Hamilton Krieger. 2006. "Implicit Bias: Scientific Foundations." California Law Review 94(4): 945-67.

Hale, Galina, and Tali Regev. 2014. "Gender Ratios at Top PhD Programs in Economics." Economics of Education Review 41: 55-70.

Haney-López, Ian. 2000. "Institutional Racism: Judicial Conduct and a New Theory of Racial Discrimination.” Yale Law Journal 109: 1717-1884.

Hoogendoorn, Sander, Hessel Oosterbeek, and Mirjam Van Praag. 2013. "The Impact of Gender Diversity on the Performance of Business Teams: Evidence from a Field Experiment." Management Science 59(7): 1514-28.

Husbands Fealing, Kaye H., Yufeng Lai, and Samuel L. Myers Jr. 2015. "Pathways vs. Pipelines to Broadening Participation in the STEM Workforce." Journal of Women and Minorities in Science and Engineering 21(4): 271-93.

Inzlicht, Michael, and Toni Schmader, eds. 2012. Stereotype Threat: Theory, Process, and Application. Oxford University Press.

Kahn, Shulamit B. 1995. "Women in the Economics Profession." Journal of Economic Perspectives 9(4): 193-206.

Kamas, Linda, Anne Preston, and Sandy Baum. 2008. "Altruism in Individual and Joint-Giving
Decisions: What's Gender Got to Do with It?" Feminist Economics 14(3): 23-50.

Kelly D. H. 1962. "Information Capacity of a Single Retinal Channel." IEEE Transactions on Information Theory 8: 221-26.

Lang, Kevin, and Jee-Yeon K. Lehmann. 2012. "Racial Discrimination in the Labor Market: Theory and Empirics." Journal of Economic Literature 50(4): 959-1006.

Leeds, Michael A. 1992. "Who Benefits from Affirmative Action? The Case of the AEA Summer Minority Program 1986-1990." Journal of Economic Perspectives 6(2): 149-56.

Leung, Angela Ka-yee, William W. Maddux, Adam D. Galinsky, Chi-yue Chiu. 2008. "Multicultural Experience Enhances Creativity: The When and How." American Psychologist 63(3): 169-81.

Levine, Sheen S., Evan P. Apfelbaum, Mark Bernard, Valerie L. Bartelt, Edward J. Zajac, and David Stark. 2014. "Ethnic Diversity Deflates Price Bubbles." PNAS 111(52): 18524-29.

Link, Albert N., Christopher A. Swann, and Barry Bozeman. 2008. "A Time Allocation Study of University Faculty." Economics of Education Review 27(4): 363-74.

MacNell, Lillian, Adam Driscoll, and Andrea N. Hunt. 2015. "What's in a Name: Exposing Gender Bias in Student Ratings of Teaching." Innovative Higher Education 40(4): 291-303.

May, Ann Mari, Mary G. McGarvey, and Robert Whaples. 2014. "Are Disagreements Among Male and Female Economists Marginal at Best?: A Survey of AEA Members and Their Views on Economics and Economic Policy." Contemporary Economic Policy 32(1): 111-32.

Milkman, Katherine L., Modupe Akinola, and Dolly Chugh. 2015. "What Happens Before? A Field Experiment Exploring How Pay and Representation Differentially Shape Bias on the Pathway into Organizations." Journal of Applied Psychology 100(6): 1678-1712.

Miller, Casey W., and K. G. Stassun. 2014. "A Test that Fails." Nature 510: 303-304.

Misra, Joya, Jennifer Hickes Lundquist, and Abby Templer. 2011. "Gender, Work Time, and Care Responsibilities Among Faculty.” Sociological Forum 27(2): 300-23.

Mitchell, Sara McLaughlin, and Vicki L. Hesli. 2013. "Women Don't Ask? Women Don't Say No? Bargaining and Service in the Political Science Profession." PS: Political Science E Politics 46(2): 355-69.

Miyake, Akira, Lauren E. Kost-Smith, Noah D. Finkelstein, Steven J. Pollock, Geoffrey L. Cohen, and Tiffany A. Ito. 2010. "Reducing the Gender Achievement Gap in College Science: A Classroom Study of Values Affirmation." Science 
330 (6008): 1234-37.

Moss-Racusin, Corinne A., John F. Dovidio, Victoria L. Brescoll, Mark J. Graham, and Jo Handelsman. 2012. "Science Faculty's Subtle Gender Biases Favor Male Students." PNAS 109(41): 16474-79.

Murphy, Mary C., Claude M. Steele, and James J. Gross. 2007. "Signaling Threat: How Situational Cues Affect Women in Math, Science, and Engineering Settings." Psychological Science 18(10): 879-85.

Phillips, Katherine W., Gregory B. Northcraft, and Margaret A. Neale. 2006. "Surface-Level Diversity and Decision-Making in Groups: When Does Deep-Level Similarity Help?” Group Processes Ẽ Intergroup Relations 9(4): 467-82.

Pope, Devin G., Joseph Price, and Justin Wolfers. 2014. "Awareness Reduces Racial Bias." CEPR Discussion Paper DP9868.

Price, Gregory N. 2009. "The Problem of the 21st Century: Economics Faculty and the Color Line." Journal of Socio-Economics 38(2): 331- 43.

Price, Joseph, and Justin Wolfers. 2010. "Racial Discrimination among NBA Referees." Quarterly Journal of Economics 125(4): 1859-87.

Purdie-Vaughns, Valerie, Claude M. Steele, Paul G. Davies, Ruth Ditlmann, and Jennifer Randall Crosby. 2008. "Social Identity Contingencies: How Diversity Cues Signal Threat or Safety for African Americans in Mainstream Institutions." Journal of Personality and Social Psychology 94(4): 615-30.

Rask, Kevin, and Jill Tiefenthaler. 2008. "The Role of Grade Sensitivity in Explaining the Gender Imbalance in Undergraduate Economics." Economics of Education Review 27(6): 676-87.

Rowe, Mary. 2008. "Micro-affirmations and Micro-inequities." Journal of the International Ombudsman Association 1(1): 45-48.

Sarsons, Heather. 2015. "Gender Differences in Recognition for Group Work." Harvard University Working Paper, December 3.

Schulman, Kevin A., et al. 1999. "The Effect of Race and Sex on Physicians' Recommendations for Cardiac Catheterization.” New England Journal of Medicine 340(8): 618-26.

Scott, Charles E., and John J. Siegfried. 2016. "American Economic Association Universal Academic Questionnaire Summary Statistics." American Economic Review 106(5): 680-82.

Sheltzer, Jason M., and Joan C. Smith. 2014. "Elite Male Faculty in the Life Sciences Employ Fewer Women.” PNAS 111(28): 10107-12.

Soll, Jack B., Katherine L. Milkman, and John W. Payne. 2014. "A User's Guide to Debiasing." Chap. 33 in vol. 2 of Handbook of Judgment and Decision Making, edited by Gideon Keren and George Wu. Wiley-Blackwell.
Sommers, Samuel R. 2006. "On Racial Diversity and Group Decision Making: Identifying Multiple Effects of Racial Composition on Jury Deliberations." Journal of Personality and Social Psychology 90(4): 597-612.

Stassun, Keivan G., Susan Sturm, Kelly HolleyBockelmann, Arnold Burger, David J. Ernst, and Donna Webb. 2011. "The Fisk-Vanderbilt Master'sto-Ph.D. Bridge Program: Recognizing, Enlisting, and Cultivating Unrealized or Unrecognized Potential in Underrepresented Minority Students." American Journal of Physics 79(4): 374-79.

Steele, Claude M., and Joshua Aronson. 1995. "Stereotype Threat and the Intellectual Test Performance of African Americans." Journal of Personality and Social Psychology 69(5): 797-811.

Steinpreis, Rhea E., Katie A. Anders, and Dawn Ritzke. 1999. "The Impact of Gender on the Review of the Curricula Vitae of Job Applicants and Tenure Candidates: A National Empirical Study." Sex Roles 41 (7/8): 509-528.

Stephens, Nicole M., and Cynthia S. Levine. 2011. "Opting Out or Denying Discrimination? How the Framework of Free Choice in American Society Influences Perceptions of Gender Inequality." Psychological Science 22(10): 1231-36.

Sziklai, George C. 1956. "Some Studies in the Speed of Visual Perception." IRE Transactions on Information Theory 2(3): 125-28.

Trix, Frances, and Carolyn Psenka. 2003. "Exploring the Color of Glass: Letters of Recommendation for Female and Male Medical Faculty." Discourse and Society 14(2): 191-220.

Turner, Caroline Sotello Viernes, and Samuel L. Myers. 2000. Faculty of Color in Academe: Bittersweet Success. Needham Heights, MA: Allyn and Bacon.

Uhlmann, Eric Luis, and Geoffrey L. Cohen. 2007. "'I Think It, Therefore It's True': Effects of Self-Perceived Objectivity on Hiring Discrimination." Organizational Behavior and Human Decision Processes 104(2): 207-223.

US Department of Education, Institute of Education Sciences, National Center for Education Statistics. No date. Integrated Postsecondary Education Data System (IPEDS). http://nces.ed.gov/ipeds/.

Vesterlund, Lise, Linda Babcock, Maria Recalde, and Laurie Weingart. 2015. "Breaking the Glass Ceiling with 'No': Gender Differences in Accepting and Receiving Requests for Non-Promotable Tasks." University of Pittsburgh, Department of Economics, Working Paper 15/005.

Watts, Michael, and Georg Schaur. 2011. "Teaching and Assessment Methods in Undergraduate Economics: A Fourth National Quinquennial Survey." Journal of Economic Education 42(3): 294-309. 
West, Jevin D., Jennifer Jacquet, Molly M. King, Shelley J. Correll, and Carl T. Bergstrom. 2013. "The Role of Gender in Scholarly Authorship." PLoS ONE 8(7): e66212.

Woolley, Anita Williams, Christopher F. Chabris, Alex Pentland, Nada Hashmi, and Thomas W. Malone. 2010. "Evidence for a Collective Intelligence Factor in the Performance of Human
Groups.” Science 330(6004): 686-88.

Wu, Stephen. 2005. "Where Do Faculty Receive Their PhDs? A Comparison across Six Disciplines." Academe 91 (4): 53-54.

Yellen, Janet L. 2014. "Welcoming Remarks." Speech at the National Summit on Diversity in the Economics Profession, Washington, DC, October 30 . 